\title{
NÍVEIS E ARTICULAÇÕES DO ARGUMENTO CONTRATUALISTA DE HOBBES
}

\author{
Delmo Mattos \\ Fundação Getúlio Vargas, UERJ, CCEAD-PUC-Rio
}

\begin{abstract}
In many cases, the contractarian argument of Hobbes is described in a superficial and general, ie, without regard to levels and joints involving his speech. This type of exposure it is absolutely fails to characterize the core of the development of theoretical and political philosopher, for signals to interpretative distortions about what he truly intends to base. Based on this point, this article aims to discuss the nuances and plots that make up the hobbesian contractarian argument to explain the basis for this argument is closely related to notions of determination and will and, secondly, the transfer and authorization as through, the latter two can be shown the close relationship of "dependency and need" between the device (Commonwealth) and the builders (artifex) justifying the purpose and actions of power sovereign.
\end{abstract}

Keyswords: contract, civil society, commonwealth, politic.

Resumo: Em muitos casos, a argumentação contratualista de Hobbes é descrita de forma superficial e generalizada, ou seja, sem atentar para os níveis e articulações que envolvem o seu discurso. Este tipo de exposição torna-se absolutamente falha ao descaracterizar 0 cerne do empreendimento teórico-político do filósofo, pois sinaliza para distorções interpretativas a respeito do que ele verdadeiramente pretende fundamentar. Baseado neste aspecto, este artigo propõe a discutir as nuances e tramas que constituem o argumento contratualista hobbesiano a fim de explicitar que a base deste argumento está intimamente relacionada às noções de deliberação e vontade e, por outro lado, a de transferência e autorização e como, por intermédio, destes dois últimos é possível demonstrar a estreita relação de "dependência e necessidade' entre o artifício (Commonwealth) e seus construtores (artifex) que justifica o sentido e as ações do poder soberano.

Palavras-chave: contrato, sociedade civil, Estado, política. 


\section{Introdução}

$\mathrm{Na}$ contemporaneidade são vários os teóricos que retomaram o argumento contratualista para explicitar ou fundamentar suas discussões políticas, morais ou econômicas. Entre os teóricos que utilizam notoriamente tal argumentação estão Rawls, Gaultier e Buchanan. Com efeito, apesar dessa retomada do argumento contratualista há uma nítida distância entre os novos teóricos do contrato social dos contratualistas clássicos modernos como Locke, Hobbes e Rousseau. Esta distância pode ser medida de diversas formas, entre elas, a mais importante é a do objeto a que visa, em cada caso, a estratégia argumentativa do contrato social.

Sabe-se que o principal objeto dos contratualistas dos séculos XVII e XVIII era a sociedade política ou o Estado propriamente dito. Neste aspecto, a sua versão moderna ou clássica, o argumento contratualista baseia-se em um ponto de vista eminentemente político. Por sua vez, nos contemporâneos, o argumento ressurge no contexto da discussão acerca dos princípios de justiça e dos fundamentos da moralidade humana, tornandose, assim, uma ampliação argumentativa do objeto original do contratualismo clássico.

Ainda que a distância entre o argumento contratualista moderno do contemporâneo exponha discrepâncias conceituais visíveis é inegável a sua consistência teórica, consistência que o manteve inabalável durante todo este tempo a ponto obter mais prestígio do que as outras formas de refletir os fenômenos sociais e políticos, tais como sociologia, a antropologia e a economia. Na certeza da veracidade de tal afirmação, a finalidade deste artigo contempla de uma forma geral, a argumentação contratualista não para enaltecer seus pressupostos e fundamentos, nem ao menos, para examinar diferenças de estilos e aproximações argumentativas entre os que utilizaram de tal artifício teórico. Ao contrário disso, o intuito é resgatar o cerne deste argumento propondo um exame pormenorizado através daquele que foi seu expoente, Thomas Hobbes.

Para este propósito busca-se evidenciar o argumento contratualista hobbesiano em seus aspectos intrínsecos sem incorrer a um exame generalista e superficial daquilo que é o elemento central da sua teoria na medida em que ressalta-se as nuances que envolvem a sua argumentação. Para tanto segue-se os seguintes passos: (1) primeiramente, parte-se do argumento sobre a possibilidade do contrato social através da explicitação 
da fórmula geral que o constitui evidenciando, sobretudo, a transformação da multidão em unidade e da expressão das vontades particulares numa vontade geral; (2) segundo, examina a possibilidade de transferência mútua de direitos e a questão da autorização concebida mediante a concepção hobbesiana de "representação política" pelo qual determina-se as razões pelas quais justificam-se o sentido e as ações praticadas pelo poder soberano.

\section{I - A possibilidade do contrato social: A expressão da vontade particular e unidade da multidão}

Em sentido amplo, tal como se compreende as doutrinas que floresceram na Europa entre o começo do século XVII e o fim do XVIII, o contrato ou pacto compreende todas aquelas teorias políticas que fundamentam a origem da sociedade e a legitimação do poder político num contrato, isto é, num acordo tácito ou expresso entre a maioria dos indivíduos, acordo que assinala efetivamente a transição do estado de natureza para o estado político ou a sociedade civil.

$\mathrm{Na}$ teoria política hobbesiana a lógica desta transição deve satisfazer a exigência de legitimar ou instaurar o poder político sem qualquer referência a um poder divino. Nisto está a originalidade do seu argumento na medida ressalta o papel da vontade humana como instrumento de ação política cuja conseqüência será a reunião da multidão ou das vontades particulares de cada um subvencionada pela especificidade que há entre um acordo e pacto.

Os pactos representam acordos da livre vontade de cada homem a serem efetuados num tempo futuro, pois nenhum homem está obrigado a cumprir a palavra dada pelo fato de se caracterizar como uma promessa futura e de nenhum poder externo obrigá-lo. Por sua vez, em relação aos acordos ninguém está obrigado e, embora eles sejam derivados da vontade, a simples desconfiança recíproca pode simplesmente anulá-los. Além disso, o contrato representa um acordo firmado no tempo presente e recorre a elementos externos para validá-lo ${ }^{1}$.

\footnotetext{
1 Vale ressaltar que a diferença entre contratos e pactos em Hobbes concerne ao tempo da ação. Com efeito, muitas vezes Hobbes não é rigoroso com sua própria terminologia, pois emprega freqüentemente o termo "contrato" para referir-se a convenções ou pactos e vice versa.
} 
Assim, ao contrário do que Aristóteles apregoava na Política, para quem o homem é um animal político, e a constituição da pólis se deve a um processo natural, para Hobbes este processo não é natural e a base do seu argumento está intimamente relacionada às noções de deliberação e vontade e, por outro lado, a de transferência e autorização. Estas noções são descritas pelo filósofo a partir de uma fórmula fundamental que perpassa todas as definições tratadas por ele em suas principais obras.

Para compreender exatamente o conteúdo de tal fórmula é necessário percorrer toda uma discussão de níveis e distinções que a constitui. Neste sentido, nos cabe impreterivelmente explicitar que o conteúdo da fórmula do contrato social hobbesiano caracteriza-se, sobretudo, pela noção de renúncia ou transferência da liberdade e do direito natural, pois, tanto um quanto o outro, são os fatores determinantes para o quadro de hostilidade generalizado que configura o estado de natureza ${ }^{2}$. Mas o que significa propriamente a noção de renúncia e transferência? Quais são os níveis e distinções que constituem o contrato social em Hobbes?

No Leviathan, capítulo XVII, Hobbes fornece os indícios em direção a uma resposta plausível a tais indagações por meio do vínculo que faz entre o elemento central da sua argumentação contratualista denominada de "fórmula elementar básica do contrato". O conteúdo desta fórmula é expresso através da seguinte sentença:

Cedo transfiro o meu direito (jus) de governar-me a mim mesmo a este homem, ou esta assembléia de homens, com a condição de transferires a ele teu direito, autorizando de maneira semelhante todas as suas ações. Feito isso, a multidão assim unida em uma só pessoa se chama Estado (Commonwealth), em latim civitas (HOBBES, 1968, Cap. XVII, p. 227).

Os contratos são instrumentos ou dispositivos artificiais que baseiam-se na transferência ou renuncia mútua de direitos, ou seja, da liberdade natural pertencente aos homens. Esta renuncia ou transferência

\footnotetext{
${ }^{2}$ Cabe assinalar que a motivação da instituição do contrato está, sobretudo, na percepção dos homens que o "estado de guerra" é inviável à preservação da sua vida.
} 
desemboca numa limitação da liberdade que, por sua vez, é conseqüência direta da expressão da vontade de cada um para realizar interesses que demonstram acima de tudo a preservação da vida e a sua manutenção confortável e digna.

Sobre isto, Hobbes se expressa do seguinte modo:

A única maneira de instituir um poder comum, capaz de defendê-los das invasões dos estrangeiros (Forraigners) e das injúrias uns dos outros, garantido-lhes assim uma segurança suficiente para que, mediante seu próprio labor graças aos frutos da terra, possam alimentar-se e viver satisfeitos, é conferir toda a força e poder a um homem, ou uma assembléia de homens, a uma só vontade (HOBBES, 1968, Cap. XVII, pp. 227-228).

Esta passagem do Leviathan está relacionada à fórmula geral do conteúdo do contrato social e pressupõe o primeiro estágio da consecução do pacto ou acordo que cada homem estabelece consigo mesmo e pelo qual obrigam a obedecer às ordens de "um certo homem ou conselho", dispondo a sua própria força e todos os seus meios a este em vista a sua proteção e segurança ${ }^{3}$.

Este primeiro estágio é deduzido a partir da percepção dos homens da inviabilidade e hostilidade presente no estado de natureza, resultando assim, uma necessidade de "auxílio mútuo" como a primeira medida viável para ultrapassar o medo da morte violenta vigente no "estado de guerra". Nestes termos, o ponto de partida da efetivação deste "auxílio mútuo" deve pressupor a vontade ou o consentimento de cada um dos homens, conforme se dão conta de que a eficácia de uma união entre eles será tanto mais possível quanto maior for o número daqueles que dirigirem as suas ações para um fim comum.

\footnotetext{
3 O sentido ao qual Hobbes refere-se aqui por segurança, deve ser entendido, de uma forma geral, não apenas a preservação da vida em qualquer condição que seja, mas a segurança com vistas à felicidade na medida em que esta deva pressupor uma vida minimamente digna (Cf. HAMPTON, 1986). Sobre isto, em outras palavras, observa Hobbes, - , mas por segurança não entendemos aqui uma simples preservação, mas também, por uma indústria legítima (lawfull industry), sem perigo ou inconveniente do Estado, adquire para si próprio (HOBBES, 1968, Cap. XXX, p. 376).
} 
Conforme indicado anteriormente é possível vislumbrar que a possibilidade do contrato em Hobbes reside, sobretudo, no consentimento ou na vontade de cada homem se unir resultando como requisito final para a segurança daqueles que estabelecem tal união a necessidade de um poder comum ou absoluto, por meio do qual "cada homem possa conservar a paz entre si mesmos e a unirem suas forças quando necessário contra um inimigo comum" (HOBBES, 1968, Cap. XVII, p. 224) ${ }^{4}$.

Pois, segundo Hobbes,

O fim último [isto é] a causa final e designo dos homens (que amam naturalmente a liberdade e o domínio sobre os outros), ao introduzir aquela restrição sobre si mesmos sob a qual os vemos viver nos Estados, é o cuidado com a própria conservação e com uma vida mais satisfeita (O grifo é nosso) (1968, Cap. XVII, p. 223).

Com efeito, a forma pela qual Hobbes expressa o consentimento é a que diz respeito à possibilidade de que as "vontades de muitos" concorram para uma e a mesma ação ou efeito, ou seja, que por vontade todas as ações humanas sejam dirigidas a um mesmo fim". Assim, uma vez que a "vontade de muitos" seja dirigida a um fim comum, diz Hobbes, “(...) isto é mais do

\footnotetext{
${ }^{4}$ Ao recusar o pactum societatis como incapaz de fundamentar uma "sociedade estável", Hobbes afirma que é necessário estipular um acordo preliminar que vise à instauração das condições necessárias para remover as causas da insegurança que constituem o estado de natureza. Portanto, ao contrário do pactum societatis, Hobbes engendra a necessidade do pactum unions (pacto de união), que é um "pacto de submissão", cujos contratantes são os homens associados entre si que estabelecem o compromisso recíproco de se submeterem a um terceiro não contratante em que resulta um poder comum através do qual ocorre a passagem do estado de natureza para a sociedade civil. Aqui já é possível vislumbrar o desenho, com a ajuda dos diversos elementos lógicos requeridos, da figura teórica de uma "sociedade política", na medida em que a união estabelecida resulta naquilo que se convencionou denominar de "corpo político" (Body politic), e que podemos defini-la como uma "multidão de homens unida como uma pessoa para a sua paz, defesa e bem comum" (Cf. BOBBIO, 1991).

${ }^{5} \mathrm{Cf}$. "Quando a vontade de muitos concorrem para uma e a mesma ação e efeito, esse concurso é denominado consenso, pelo qual nós não devemos entender uma vontade de muitos homens, pois todo homem tem várias vontades, mas muitas vontades para a produção de um efeito. Mas quando as vontades de dois homens diferentes produzem certas ações que reciprocamente se anulam uma a outra, a isto se dá o nome de contenda. Estando as pessoas umas contra as outras, batalha. Ao passo que as ações que procedem constituem auxílio mútuo. Quando muitas vontades estão envolvidas ou inseridas na vontade de uma ou mais pessoas em consenso (o que, quando puder acontecer, será daqui por diante declarado), então esse envolvimento de muitas vontades numa só ou maior é chamada união" (HOBBES, 2002b, I, Cap. XII, p. 85).
} 
que consentimento ou concórdia, é uma verdadeira unidade de todos eles, numa só e mesma pessoa, realizada por um pacto de cada homem como todos os homens (...)" (Cf. Idem., Ibidem.).

Sendo assim, a unidade expressa como uma "vontade de muitos" possibilita que a vontade de um certo número de homens seja compreendida como a vontade de um "único homem", e por sua vez, que esta seja a expressão da vontade de cada homem, conforme a vontade desse "único homem" subentende-se como a expressão da vontade de cada homem que a consentiu. Dito isto, é possível afirmar que, para Hobbes, uma multidão de homens transforma-se numa "pessoa artificial" a partir do momento em que esta é representada por uma assembléia ou unicamente um homem, mas que esta representação seja por consentimento de todos aqueles que participam de tal multidão.

No entanto, a única forma de se conceber a unidade daquela multidão é mediante a sua representação, constituída em uma "pessoa artificial", pois, segundo Hobbes, é a unidade do representante e não a unidade do representado que possibilita que uma pessoa seja una (Person one) (HOBBES, 1968, Cap. XVI, p. 220). Nestes termos, designar um homem ou uma assembléia de homens como representante legítimo, é o mesmo que dizer que esta representação é capaz de reduzir as diversas vontades contidas na multidão em uma única vontade expressa na pessoa representante do poder soberano.

Esta determinação, portanto, configura o segundo estágio da realização efetiva daquele acordo ou contrato, pois expressa a exigência lógica de "totalidade contida na unanimidade", ou seja, trata-se de obter de todos o que cada homem obteve de si próprio e estender para aos demais a conseqüência disso (Cf. Idem., Ibidem.).

De acordo com Hobbes,

A realização da união consiste nisso, que todo homem, pela convenção, obrigue a si mesmo a um mesmo homem, e a um e o mesmo conselho, por meio de quem todos são nomeados e determinados a fazer aquelas ações que o dito homem ou conselho deverá ordená-lo a fazer e a não fazer, que ele ou eles deverão proibir, ou ordená-los a não fazer. (...) É por isso que aquele que comanda pode, pelo uso de todos os seus meios e força, habilitar-se pelo terror a moldar a vontade de 
todos aqueles pela unidade e a concórdia, entre eles mesmos. (2002b, I, Cap. XIX, p. 131).

O segundo estágio do contrato é o primeiro na ordem de constituição propriamente da "verdadeira unidade" no qual é possível vislumbrar a caracterização, levando em conta os diversos elementos já evidenciados, da figura teórica do que Hobbes caracterizará de sociedade civil ou o que para os gregos consiste a pólis, ou seja, a cidade, e que para o filósofo em questão pode ser caracterizada como uma "multidão de homens" unidos como uma pessoa mediante um poder comum ou absoluto para assegurar a paz e a defesa do "bem comum" (HOBBES, 2002b, I, Cap. XIX, p. 131).

Com base nisso, podemos inferir que, por um lado, no que diz respeito à união evidencia-se um acordo que Hobbes concebe como prévio ao pacto maior ("pacto de submissão") que constituirá a sociedade civil, pacto este que se efetiva em cada homem para consigo mesmo e consiste na disposição para renunciar a liberdade e o direito natural, por outro lado, e, conseqüentemente, todos os membros dessa união estão obrigados logicamente a pactuar e cumprir a condição para que se estabeleça tal poder comum ou absoluto (Idem., Ibidem., I, Cap. XV, p. 101).

Segundo Hobbes,

Uma das leis naturais inferidas desta primeira e fundamental é a seguinte: que os homens não devam conservar o direito que têm, todos, a todas as coisas, e que alguns desses direitos devem ser transferidos, ou renunciados. Pois, se cada um conservasse seu direito a todas as coisas, necessariamente se seguiria que alguns teriam direito de invadir, e outros, pelo mesmo direito, se defenderiam daqueles (pois todo homem por necessidade natural, empenha-se por defender o seu corpo e as coisas que julga necessárias para protegê-lo). Disso se seguiria a guerra. Age, pois contra a razão da paz, isto é, contra a lei da natureza, todo aquele que não abre a mão de seu direito a todas as coisas (HOBBES, 2002a, p. 39). 
Ora, abrir mão do direito a todas as coisas é agir em favor da paz conforme aquele preceito ditado pela reta razão ${ }^{6}$. Enquanto as concepções tradicionais de lei da natureza a posicionam em vistas a um fim supremo como aquilo que é considerado como um bem em si mesmo, em Hobbes, ao contrário, esta é posicionada na aquisição da paz e da segurança. Não obstante, a instauração da paz surge no seio da reflexão hobbesiana como conseqüência direta da necessidade de garantir aos homens os meios de obterem o fim maior o qual perseguem segundo prescreve a primeira lei da natureza. Desta lei fundamental da natureza, que prescrevem aos homens que "procurem a paz e a sigam" Hobbes deriva a segunda lei da natureza, a saber:

Que um homem esteja de acordo, quando outros estão assim também, tanto quanto a sua paz e defesa ele pense ser necessário, renunciar este direito a todas as coisas; e contentar-se com a mesma liberdade em comparação com os outros homens do mesmo modo que ele permita [aos] outros homens em comparação a si mesmos. Porque enquanto todo homem conservar seu direito, de fazer qualquer coisa que ele queira; todos os homens se encontrarão na condição de guerra. Mas se os outros homens não renunciarem a seu direito, assim como ele próprio, nesse caso não há razão para que alguém se prive do seu, pois isso equivaleria a oferecerse como pressa (coisa a que ninguém é obrigado), e não dispor-se (sic) para a paz (...). (HOBBES, 1968, Cap. XIV, p. 190).

No conteúdo da segunda lei da natureza já se encontra subentendida a conseqüência direta acerca da inviabilidade da liberdade natural, na medida em que desta se deduzem as indicações de caso seja possível o estabelecimento da paz, cada homem deve renunciar o seu direito e a sua liberdade natural. Por outro lado, esta também introduz um elemento fundamental que merece ser destacado, pois nesta se encontra em linhas gerais a lógica do que vem a ser o contrato social. Tal elemento

\footnotetext{
${ }^{6}$ De acordo com Hobbes, tal ditame é uma lei constitutiva da natureza humana tanto quanto qualquer outra faculdade do homem (HOBBES, 2002a, p. 33).
} 
fundamental diz respeito à "renúncia do direito original", ou a aquilo que denominamos de restrição ou limitação da liberdade natural.

Neste momento poderíamos fazer a seguinte indagação: como se efetiva a transferência da liberdade e do direito natural segundo a argumentação hobbesiana do contrato social? Qual é a relação desta transferência e limitação da liberdade com o processo de autorização das ações para um ente artificial? A fim de responder a estes questionamentos, parte-se da exposição acerca do núcleo central daquilo que é a "representação política" em Hobbes. Para tanto, discute-se a relação de representatividade com base na relação de dependência entre o artifício, ou seja, o Commonwelth e os seus construtores através do qual explica-se o sentido e a finalidade das ações do poder soberano em relação aos súditos ou cidadãos.

\section{II - A lógica do contrato social: a transferência mútua de direitos e a autorização política}

A questão relativa ao processo de autorização de ações e, consequentemente, a transferência de direitos e poderes de cada homem no contexto do estado de natureza requer algumas noções de "renúncia" e "transferência" na teoria política de Hobbes. Poderia haver algum tipo de diferença entre tais conceitos? Como eles estão dispostos na argumentação do filósofo de Malmesbury? De maneira geral, a resposta a tal indagação pode ser explicitada pelas próprias palavras de Hobbes tanto no De Cive quanto no Leviathan.

No De Cive, ele assevera:

Diz-se que abre mão de seu direito quem a ele renuncia de forma absoluta, ou a transfere a outrem. Renuncia absolutamente a seu direito quem, por sinal suficiente ou símbolos adequados, manifesta a vontade de que deixe ser lícito (lawful) ele fazer aquilo a que antes tinha direito. Esse transfere seu direito àquele que, por sinal suficiente ou símbolos adequados, declara a outro que é a sua vontade que se torne ilícito ele resistir-lhe, naquilo em que antes poderia resistir. A transferência de direito consiste na não-resistência - isso porque, já antes de ocorrer a transferência, seu beneficiário detinha, também ele, direito a tudo, de modo 
que ele não poderia conferir nenhum direito novo. Apenas o direito de resistência, que aquele que transferiu o direito antes possuía, e que impedia o outro de livremente desfrutar de seus próprios direitos, agora completamente abolido (HOBBES, 2002a, pp. 39-40).

Por sua vez, no Leviathan, Hobbes explica o significado de "transferência" e "renúncia" com base, sobretudo, no objeto ou no beneficiário desses elementos:

\begin{abstract}
Abandona-se o direito simplesmente renunciando a ele, ou transferindo-o a outrem. Simplesmente renunciando, quando não importa em favor de quem irá redundar o respectivo beneficio. Transferindo-o, quando com isso se pretende beneficiar uma determinada pessoa ou pessoas. Quando de qualquer destas maneiras alguém abandonou ou adjudicou seu direito, diz-se que fica obrigado ou forçado a não impedir àqueles a quem esse direito foi abandonado ou adjudicado o respectivo beneficio, e que deve, e é seu dever, não tomar nulo esse seu próprio ato voluntário; e que tal impedimento é injustiça e injúria, dado que é sine jure, pois se transferiu ou se renunciou ao direito (HOBBES, Cap. XIV, pp. 190-191. Grifo do autor).
\end{abstract}

Conforme exposto, o contrato corresponde exatamente ao modo como Hobbes entende a "transferência mútua de direitos"7. Este direito nada mais é do que a liberdade natural, assim, renunciar direitos, para o filósofo, consiste em ao mesmo tempo em renunciar a liberdade natural que por direito cada homem possuí no contexto do estado de natureza. Ora, renunciar ou transferir o seu direito e a sua liberdade natural os homens restringem ou limitam o seu "poder natural" ou a sua "potência natural" em favor da sua segurança e a preservação da vida, longe da situação insustentável do "estado de guerra".

\footnotetext{
7 Por meio do argumento do contrato social, será possível Hobbes evidenciar a razão pela qual a liberdade natural constitui-se na sua teoria de política como um fator estritamente negativo no que concerne à manutenção da vida e a preservação da paz entre os homens.
} 
Disso resulta o conteúdo do contrato social concebido por Hobbes como uma transferência ou "renúncia mútua" de cada homem ao seu direito legítimo de utilizar irrestritamente o poder ou "potência natural" (potentia naturale) como meio de preservação do movimento natural, isto é, como meio de preservação da vida em nome de uma "entidade artificial" (Commonwealth) personificada no soberano.

No entanto, é preciso entender que, na verdade, é impossível a qualquer homem transferir ou renunciar realmente a sua própria força (potentia) para outro, ou mesmo para este outro recebê-la, sendo assim, deve-se entender que o significado de "transferência" ou "renúncia" da liberdade e do direito natural (como também a força e o "poder natural") não é mais, para quem os transfere ou renuncia do que se abdicar ou renunciar a seu próprio direito de resistir ${ }^{8}$. Neste caso, afirmar que os homens transferem ou renunciam sua liberdade e direitos nada mais é do que um modo intuitivo de mostrar que a parte que transferiu o seu direito se abstém dele, ou seja, se abstém voluntariamente de uma ação.

Neste sentido, não se pode dizer que realmente se transferiu a liberdade e o direito natural a um poder comum ou absoluto, pois este é somente a figura que resulta daquela suposta renúncia de cada homem ao direito natural de usar indiscriminadamente a sua própria força ou "poder natural" para resistir aquele a quem ele pode transferir esse direito natural. Em outros termos, o poder comum ou absoluto (soberano) é a soma cujas parcelas são a liberdade e o direito a que cada homem renunciou.

Através dessa metáfora, supõe-se que tal como a soma se constitui por suas parcelas, assim o poder comum ou absoluto é constituído pela renúncia da liberdade e do direito natural de cada homem. Então, pode-se deduzir, também, que cada homem que renunciou à sua liberdade e ao seu direito natural constitui tal poder comum ou absoluto. Em outras palavras, cada homem que renunciou tanto à sua liberdade e ao seu direito natural constituem a si próprio como possuindo um poder absoluto e soberano 9 .

\footnotetext{
${ }^{8} \mathrm{Cf}$. "Para a transferência do direito, portanto, duas coisas são necessárias: uma da parte daquele que transfere que é a suficiente significação da sua vontade em transferi-lo; outra, da parte daquele a quem o direito é transferido, que é a suficiente significação de que o aceita" (HOBBES, 2002b, Cap. XV, p. 101).

${ }^{9} \mathrm{Cf}$. "Aquele que outorga, promete ou pactua com alguém e, posteriormente, outorga, promete ou pactua o mesmo a outra pessoa, torna nulo o último ato. Pois é impossível para um homem transferir
} 
No The Elements of Law Hobbes expressa este ponto da seguinte forma:

O fim pelo qual um homem outorga ou transfere para outro, ou outros, o direito de proteger e defender a si mesmo por intermédio de sua própria capacidade, é a proteção que ele, através dessa transferência, espera para ser protegido e defendido daqueles a quem ele transferiu o direito. E um homem pode, então, considerar a si mesmo no estado de proteção, quando puder antever que nenhuma violência lhe será feita, em vez de seu agressor não ter como ser detido pelo poder daquele soberano, a quem cada um deles se sujeitou. (...), portanto, na construção de uma república (Commonwealth), quanto mais os homens se sujeitarem sua vontade ao poder de outrem, deve ser manifesto o seu fim, a saber, a proteção. Pois, qualquer coisa que seja necessário transferir por meio da convenção para que se atinja aquela, deve ser transferida ou, ainda, cada homem estará na sua liberdade natural de proteger a sim mesmo (HOBBES, 1968, Cap. XIX, p. 136).

O escopo do acordo estabelecido entre os homens acaba por revelar a estreita relação entre o conteúdo do contrato e a noção de autorização. Através da exposição dessa relação fica evidente o modo como Hobbes estabelece $\mathrm{o}$ intercâmbio entre autor $\mathrm{e}$ ator, entre representado $\mathrm{e}$ representante cuja expressão da "vontade do soberano" vem a ser a vontade de todos, pois na medida em que cada homem confere a um representante comum sua própria autoridade particular transforma esta particularidade em uma vontade comum onde "cada súdito é o autor das ações do soberano".

Esta idéia é fundamental para a compreensão da transformação da multidão em união, pois uma multidão transforma-se em uma unidade quando há uma representação consentida de cada um dos que constitui tal multidão. Desse modo, designar um homem ou uma assembléia de homens como representante legítimo, é o mesmo que dizer que esta representação é capaz de reduzir as diversas vontades presentes na multidão em uma única

aquele direito que ele próprio não possui. E aquele direito que ele não possui, ele próprio já transferiu antes" (HOBBES, 1968, Cap. XV, p. 104). 
vontade expressa na pessoa representante do poder soberano. Por esta razão, aquele que diz ser portador de tal pessoa, seja este um homem ou uma assembléia de homens, é denominado por Hobbes de soberano, a quem pertence o poder soberano.

De outro modo, todos aqueles destituídos de tal poder soberano, são denominados de súditos ou cidadãos. Sendo, portanto, as ações praticadas pelo poder soberano ações, também, daqueles a quem o consentiu praticálas, temos que aceitar a premissa de que o soberano ao agir não age contra a vontade daqueles que o consentiram agir.

Ora, se o soberano não age contra a vontade de quem consentiu a agir, isto implica que suas ações só fazem sentido se forem direcionadas em beneficio daqueles que consentiram a autoridade agir em seu nome. Disso reside a pressuposição de que a relação de representação política impõe-se uma nítida relação de dependência e necessidade entre as ações do Estado com a vontade dos súditos ou cidadãos que o constituem (TERREL, 1994, p. 215). Neste processo, a transferência parcial dos seus poderes e direitos de cada homem, por meio do acordo ou contrato firmado assinala a efetiva autorização através do qual o autorizado é gerado e as suas ações passam a representar, de maneira absoluta, a vontade dos autores da "representação política".

Cabe dizer que nesta representação uma única vontade constitui a vontade de todos e, por isso, é denominada por Hobbes de união. Por sua vez, esta união é compreendida por Hobbes como a própria sociedade civil ou uma "pessoa artificial" uma vez que, para ele, quando há uma só vontade entre os homens, esta deve ser considerada como uma vontade única distinguindo das vontades particulares que cada um possuía antes. De posse dessas considerações é possível conceber que o Estado civil é gerado e constituído quando uma multidão de homens institui um representante e aceita todos os seus atos e decisões como se fossem os seus próprios. Em decorrência disso, surgem todos os direitos e faculdades do poder soberano ou daqueles a quem tal poder é confiado, isto é, "um homem ou uma assembléia de homens” (HOBBES, 1968, Cap. XVII, pp. 228-229).

Contudo, o representante que por vontade de cada homem decide acatar seus atos e decisões como se fossem os seus próprios constitui uma "pessoa" ou "pessoa artificial" no qual Hobbes enfatiza ser o representante legítimo do que denomina de Commonwealth. Isto explica o motivo pelo qual as três definições atribuídas nas três obras principais do projeto 
filosófico de Hobbes Leviathan, no De Cive e nos The Elements of Law, encontramos sempre subtendido a relação conceitual entre o que este define por Estado (Commonwealth) com a concepção de "pessoa artificial".

A analogia estabelecida entre o que Hobbes concebe por "pessoa artificial" e o representante legítimo do Commonwealth remete-nos diretamente ao núcleo central daquilo que denomina-se de "representação política". Mediante a concepção hobbesiana de "representação política" é possível, portanto, evidenciar uma relação de dependência entre o artifício e os seus construtores através dos quais se explicam o sentido e a finalidade das ações do poder soberano ${ }^{10}$. O primeiro passo na demonstração desse argumento consiste em identificar como Hobbes define e o que entende por "pessoa" ou "pessoa artificial". No Leviathan, Hobbes se expressa sobre isto da seguinte forma:

Uma pessoa é aquela cujas palavras ou ações são consideradas quer como suas próprias quer como representando as palavras ou ações de outro homem, ou de qualquer outra coisa a que sejam atribuídas, seja com verdade ou por ficção (HOBBES, 1968, Cap. XVI, p. 217).

Após definir o que concebe por "pessoa" ou "pessoa artificial", Hobbes recorre à distinção presente entre "pessoa artificial" e "pessoa natural" para demonstrar, enfim, o que concebe por "representação política". Conforme este menciona, uma "pessoa natural" é aquela cujas palavras e ações são consideradas como sendo próprias dela, em contrapartida, uma "pessoa artificial' consiste naquela cujas palavras e, sobretudo, as suas ações são consideradas como uma representação das palavras e ações de outro ${ }^{11}$.

\footnotetext{
10 De acordo com Bobbio (1991, p. 164), "o tema da representação é um tema central na filosofia política de Hobbes, já que a pessoa moral por excelência é o Estado. Ora, esta definição, por assim dizer, é prenunciada pelo que se lê no capítulo XVI do Leviatã (...)".

11 Cf. "When they are considered as his own, then is he called a natural person: and when they are considered as representing the words and actions of another, then is he a feigned or artificial person.. The word person is Latin, instead whereof the Greeks have prosopon, which signifies the face, as persona in Latin signifies the disguise, or outward appearance of a man, counterfeited on the stage; and sometimes more particularly that part of it which disguiseth the face, as a mask or vizard: and from the stage hath been translated to any representer of speech and action, as well in tribunals as theatres. So that a person is the same that an actor is, both on the stage and in common conversation; and to personate is
} 
Uma vez explicitadas as distinções entre "pessoa artificial" e "pessoa natural", Hobbes procura ressaltar a especificidade concernente à concepção de "pessoa artificial" utilizando como recurso demonstrativo o cenário teatral $^{12}$. Assim, como em um palco de teatro em que o ator representa um personagem, no âmbito político, também, uma pessoa pode ser representada por outra. Contudo, diferentemente do teatro, é necessário, no âmbito política, "que aquele aquém se atribui as palavras e ações tenha antes consentido que estas sejam consideradas como sendo suas" (1968, Cap. XVI, p. 217).

Desse modo, o que parece caracterizar a especificidade de uma "pessoa artificial" ou o Commonwealth em relação à "pessoa natural" é a "não identificação entre ator e autor, entendendo por ator aquele que age em nome de outro e, por autor aquele que fornece ao ator a autoridade de agir em seu nome" (ZARKA, 1955, p. 212). De acordo com esta consideração, na relação de "representação política" entende-se que o ator é aquele que, por direito e consentimento, possui autoridade de agir em nome do representado, e o autor é aquele cuja função nesta relação é de conferir ao representante a autoridade de agir em seu nome. Em vista disso, ao equiparar o direito de um de agir com o direito de possuir palavras e ações de outro, Hobbes acaba por ressaltar o que concebe por autoridade (Authoritas) $)^{13}$.

Porque aquele a quem pertencem bens e posses é chamado proprietário, em latim, Dominus, e em grego Kyros; quando

\footnotetext{
to act or represent himself or another; and he that acteth another is said to bear his person, or act in his name (in which sense Cicero useth it where he says, Unus sustineo tres personas; mei, adversarii, et judicis- I bear three persons; my own, my adversary's, and the judge's), and is called in diverse occasions, diversely; as a representer, or representative, a lieutenant, a vicar, an attorney, a deputy, a procurator, an actor, and the like" (HOBBES, 1968, Cap. XVI, pp. 227-228. Grifo do autor).

12 No The Elements of Law, Hobbes explica esta questão da seguinte forma: "Portanto, quando alguém disser que um grupo de homens realizou alguma ação, deve-se entender com isso que cada homem em particular naquele momento consentiu com a ação, e não, apenas, que a maioria o fez" (2002b, Cap. I, Parte II, p. 135).

${ }^{13}$ Cf. "(...) author no less than if he had made it himself; and no less subjecteth him to all the consequences of the same. And therefore all that hath been said formerly (Chapter XIV) of the nature of covenants between man and man in their natural capacity is true also when they are made by their actors, representers, or procurators, that have authority from them, so far forth as is in their commission, but no further. And therefore he that aketh a covenant with the actor, or representer, not knowing the authority he hath, doth it at his own peril. For no man is obliged by a covenant whereof he is not author, nor consequently (...) (HOBBES, 1968, Cap. XVI, p. 218. Grifo do autor).
} 
se trata de ações é chamado autor. E tal como o direito de posse se chama domínio, assim também o direito de fazer qualquer ação se chama autoridade (HOBBES, 1968, Cap. XVI, p. 218).

Conforme relata tal passagem, por "autoridade" deve-se entender aquele que por direito pratica qualquer ação ou, em outros termos, uma ação praticada por autoridade, deve-se sempre entender que foi realizada por consentimento daquele a quem pertencia tal direito de praticá-la. Ora, se quem pratica uma ação com autoridade pratica por consentimento de outro, então, devemos pressupor que, esse outro pratica uma ação por autoridade através daquele a quem consentiu praticar a referida ação (Cf. BOBBIO, $1991)^{14}$. Tal conseqüência explica as seguintes palavras de Hobbes:

Dado que uma multidão naturalmente não é uma, mas muitos, eles não podem ser entendidos como uma só, mas como muitos autores, de cada uma das coisas que o representante diz ou faz em seu nome. [Pois] cada homem confere a seu representante comum sua própria autoridade em particular, e a cada um pertencem todas as ações praticas pelo representante, caso the haja conferido autoridade sem limites (1968, Cap. XVI, p. 220).

Dito isto, é possível afirmar que, para Hobbes, uma "multidão de homens" transforma-se numa "pessoa artificial" a partir do momento em que esta é representada por uma assembléia ou unicamente um homem, mas que esta representação seja por consentimento de todos aqueles que participam de tal "multidão" (Cf. PIKIN, 1964). Desse modo, a única forma de se conceber a "unidade daquela multidão" é mediante a sua representação, constituída em uma "pessoa artificial", pois, segundo Hobbes, "é a unidade do representante" e "não a unidade do representado

\footnotetext{
14 Segundo Pitkin (1964, p. 330), "A person, then, is performer of actions or speaker of word, like the driver of a car. But the question of ownership-of the action or the vehicle-remains open. Explicitly, Hobbes defines it in both cases in terms of having a right; the "right of ownership" over the car, the right to do the action. But if we consider4 the kind of situation in which it becomes important who owns car, we see there is more to ownership than rights".
} 
que possibilita que uma pessoa seja uma (Person one)" (HOBBES, 1968, Cap. XVI, p. 220).

Nestes termos, designar um "homem ou uma assembléia de homens" como representante legítimo é o mesmo que dizer que esta representação é capaz de reduzir as diversas vontades presentes na multidão a uma única vontade expressa na pessoa representante do poder soberano. Por esta razão, aquele que se diz ser portador de tal pessoa, seja este um "homem ou uma assembléia de homens", é denominado por Hobbes de soberano, a quem pertence o poder soberano ${ }^{15}$. De outro modo, todos aqueles destituídos de tal poder soberano, são denominados de súditos ou cidadãos. Sendo, portanto, as ações praticadas pelo poder soberano ações, também, daqueles que consentiram praticá-las, temos que aceitar a premissa de que o soberano ao agir não age contra a vontade daqueles que lhe consentiram agir.

Ora, se o soberano não age contra a vontade de quem consentiu a agir, isto implica que suas ações só fazem sentido se forem direcionadas em beneficio daqueles que consentiram à autoridade agir em seu nome. Desse modo, esta objeção contradiz em larga medida os defensores do argumento de que o poder soberano age de forma arbitrária, entendendo aqui por agir de forma arbitrária uma ação praticada sem o prévio consentimento ou uma ação praticada contra a vontade de quem consentiu que fosse praticada em seu nome. Disso reside a pressuposição de que a relação de "representação política" o filósofo deixa transparecer uma nítida relação de "dependência e necessidade", entre as ações do Estado e a vontade dos súditos ou cidadãos que o constituem (TERREL, op. cit., p. 215).

Esta relação é resultado da transferência parcial dos seus poderes e direitos de cada homem, por meio do contrato social firmado assinala a efetiva autorização em que o "autorizado é gerado e as suas ações passam a representar, de maneira absoluta, a vontade dos autores da representação" $\left(\right.$ BERNARDES, 2002, p. 47) ${ }^{16}$. É, portanto, neste sentido que a "pessoa artificial" instituída através de um acordo firmado entre cada homem é

\footnotetext{
15 Na visão de Polin (1953, p. 223), "Persone naturelle et agent physique done coincider em fait, mais demeurent distincts em droit. Hobbes met à profit cette distintion em tenant pour personne artificielle, l'agent physique. L'acteur, don't les paroles et les actions represent les paroles ou les actions de lácteur. L'artilice est double ici: il évoque, d'une part, la persona, le déguisement ou le masque de l'acteur qui souligne aussi bien l'artilice que la lection de l'ideé de personna; mais il situe également la notion de personne dans la societé artilicielle, instituée par l'homme artiste et constructeur, l'artificer di Leviathan". 16 Ver HOBBES (1968) e TERREL (1994).
} 
resultante da vontade humana e que, nas palavras de Bernardes, "não possui a sua existência independente" daqueles que o confeccionam, "pois a sua gênese depende incondicionalmente da existência destes desde aquele momento específico da sua confecção - o contrato social - assim como pela finalidade com a qual este foi confeccionado e que determina o sentido de suas ações: a preservação da vida de cada homem que o constitui e como súditos ou cidadãos o compõe" (Idem, Ibidem, p. 46). Este argumento nos remete impreterivelmente ao contexto da física hobbesiana, uma vez que envolve a questão da "identidade e unidade" de um corpo finito ao qual o filósofo deduz o "axioma da identidade"17.

Em conformidade intelectual com o advento das novas concepções da ciência da sua época, Hobbes adota como princípio a sentença de que todo corpo busca manter um equilíbrio constante de suas diferentes partes mantendo a sua identidade. Derivada da concepção mecanicista em que Hobbes postula que tudo o que há no universo são corpos e movimento, o "axioma da identidade", aplicado à sua teoria política, converte-se no modelo explicativo para a questão da "autopreservação humana". Sabemos que o ser humano, sob o aspecto do mecanicismo hobbesiano, deve ser concebido como um sistema complexo, no qual a sua identidade depende necessariamente de "um certo nível de distribuição permanente de energia para todas as suas partes, alimentando assim o sistema como um todo" (BARBOSA FILHO, 1989, p. 63).

Considerando a relação entre os "corpos vivos", animados e finitos sob a perspectiva do "axioma da identidade", inferimos que a manutenção da vida de um corpo animado supõe o seu esforço para obter uma quantidade de força ou de poder a fim de distribuí-los por suas partes

\footnotetext{
${ }_{17} \mathrm{Cf}$. (...) they will have the same idea of the thing as the idea by virtue of which they would call it a 'body', now that we have imposed names on things. Coming nearer, they will see the same thing somehow changing its position, and they will have a new idea of it, by virtue of which they now call such a thing 'animated'. Then, standing close up, they would see its shape, hear its voice, and perceive other things which are signs of a rational mind, and would have yet a third idea, even if it had not yet been given a name - that is, the same idea on account of which we say something is 'rational'. Finally, when they conceive the whole thing as a unity, which is now seen completely and [4] distinctly, this last idea is a compound of the preceding ones. This is how the mind makes compounds of the above ideas, in the same order as the individual names body, animated, and rational are in language compounded into the single name rational-animated-body, or human-being (HOBBES, 1966, I, Cap. I, art. 3).
} 
constitutivas de modo que as conservando, preserva-se a si mesmo como uma unidade idêntica durante o período da sua existência ${ }^{18}$.

Dessa forma, o poder de autoconservação constitui-se por uma aptidão natural de obtenção e distribuição permanente de energia que os corpos finitos dispõem. Disso segue que a relação do incremento deste poder é proporcional ao incremento da "capacidade de distinção e identidade de uma coisa particular". Com efeito, o movimento que um "corpo animado" realiza no sentido de preservar-se, enquanto uma "unidade idêntica" é o mesmo que preservar a sua identidade como um "ser finito", pois, segundo Barbosa Filho "essa tendência faz parte da definição de que é ser uma coisa distinta e identificável" $(1989, \text { p. } 64)^{19}$.

Sendo assim, a relação que o Estado concebido como um "corpo artificial" (constructo) mantém com a matéria que o compõe como súditos ou cidadãos é a mesma que um "corpo animado" mantém com as partes que o constituem. Neste sentido, o Estado como qualquer "corpo animado" ao necessitar manter a sua "identidade e unidade" tende a preservar da melhor forma possível o movimento interno e específico que o compõe, isto é, a vida $^{20}$. Em outros termos, o que se quer enfatizar é que a finalidade última do Estado coincide formalmente com a finalidade fundamental de cada um que o constitui, uma vez que a manutenção da sua existência depende necessariamente da vida daqueles que o compõem (Cf. BERNARDES, op. cit.) ${ }^{21}$.

\footnotetext{
${ }^{18} \mathrm{Cf}$ (...) they will have the same idea of the thing as the idea by virtue of which they would call it a 'body', now that we have imposed names on things. Coming nearer, they will see the same thing somehow changing its position, and they will have a new idea of it, by virtue of which they now call such a thing 'animated'. Then, standing close up, they would see its shape, hear its voice, and perceive other things which are signs of a rational mind, and would have yet a third idea, even if it had not yet been given a name - that is, the same idea on account of which we say something is 'rational'. Finally, when they conceive the whole thing as a unity, which is now seen completely and [4] distinctly, this last idea is a compound of the preceding ones. This is how the mind makes compounds of the above ideas, in the same order as the individual names body, animated, and rational are in language compounded into the single name rational-animated-body, or human-being (HOBBES, 1966, I, Cap. I, art. 3).

${ }^{19}$ De acordo com Barbosa Filho: "(...) quanto maior for o poder de autoconservação da coisa particular face às causas exteriores, mais realidade terá a coisa e mais claramente ela poderá ser distinguida como possuindo natureza e uma individualidade definida" (1989, p. 63).

20 Lembro que para Hobbes, a vida nada mais é do movimento.

${ }^{21}$ Hobbes considera o ser humano como um ser natural, e como tal está condicionado às mesmas leis e aos princípios que regem os fenômenos naturais porque compartilha certos aspectos e propriedades gerais com os objetos da classe dos corpos em geral: o princípio universal dos corpos, isto é, o movimento. Contudo, Hobbes divide a classe dos corpos em geral em dois subconjuntos distintos caracterizados pelo subconjunto dos corpos inanimados e animados. Considerando, portanto, os seres
} 
Nas palavras de Hobbes no Leviathan:

A tal ponto que este condicionamento [bens e riquezas] é como se fosse a corrente sangüínea de um Estado, pois é de maneira semelhante que o sangue natural é feito dos frutos da terra; e, circulando, vai alimentando pelo caminho todos os membros do corpo do homem (...) E também nisto o homem artificial conserva sua semelhança com o homem natural, cujas veias recebem o sangue das diversas partes do corpo e o transportam até o coração; e depois de vitalizá-lo o coração volta a expelir o sangue por meio das artérias, a fim de vivificar e tornar possível o movimento a todos os membros do corpo (1968, Cap. XXIV, p. 300).

Diante desta passagem, há de se considerar que o esforço que o Commonwealth realiza para a distribuição de força ou poder entre as suas partes constitutivas (os súditos ou cidadãos) se efetiva na forma de "garantias individuais" que promovem as condições pelas quais cada um pode conservar da melhor forma possível e mais dignamente a sua vida. Desse modo, a renúncia do estado de natureza, no qual se encontravam os homens e, posteriormente a instauração do Commonwealth e a efetivação da sua soberania, representa um abandono daquela "condição miserável" em que nenhum destes realmente poderia ter a esperança de uma vida segura, próspera e confortável ${ }^{22}$.

Por esta razão, a instância do domínio (Dominium) justifica-se pela própria finalidade pela qual foi constituído, que reside no poder de restringir pela sua potência aquela liberdade absoluta incompatível com a fruição de uma felicidade efetivada mediante o estabelecimento da paz e da segurança garantidas pelo Estado. Logo, o sentido que Hobbes atribui ao poder soberano, ainda que absoluto, não se refere ao "deleite do príncipe, mas ao beneficio comum" (HELLER, 1968, p. 89) ${ }^{23}$.

humanos como pertencente a um subconjunto da classe dos corpos animados, caracterizado pelos corpos finitos e racionais.

22 De acordo com Lebrun (1984, pp. 36-37), "Segurança e a possibilidade de gozar ao máximo, em paz, de todas as "comodidades da vida", são estes os dois objetivos que os homens abandonam o estado de natureza e se tornam cidadãos".

${ }^{23}$ No De Cive, Hobbes trata esta questão da seguinte forma: "Assim, como o domínio foi constituído para proporcionar a paz, e a paz foi procurada para o bem da sociedade, todo aquele que, numa posição 
À medida que evidencia-se o processo de constituição da "pessoa artificial" por intermédio dos conceitos de "autorização" e "representação política" foi possível, portanto, demonstrar a estreita relação de “dependência e necessidade' entre o artifício (Commonwealth) e seus construtores (artifex) que justifica o sentido e as ações do poder soberano. Diante disso, ficou claro que as ações do poder soberano dirigem-se, sobretudo, a preservar a vida dos súditos ou cidadãos que o constituíram, uma vez que ao assegurar este direito necessariamente tende a preservar-se enquanto uma "unidade política" ou, enquanto "pessoa artificial".

Desta relação de "dependência e necessidade" entre o artifício (Commonwealth) e os seus construtores ressaltamos, por conseguinte, que o estabelecimento das condições necessárias e suficientes para a viabilidade do exercício possível da liberdade está fundamentalmente relacionado à constituição do Estado civil, na medida em que o uso legítimo das suas leis civis fornece impreterivelmente as garantias suficientes para o estabelecimento da paz e a manutenção da vida, inviável no estado de natureza.

Com base nisso, ficou claro que o Estado concebido por Hobbes não possui a sua existência independente dos homens que o instituem como súditos ou cidadãos e, por outro lado, não há outro modo de se estabelecer aquelas condições necessárias para a conservação da vida e, conseqüentemente, para a realização segura do exercício das faculdades naturais humanas, se não pela submissão consentida da vontade de cada homem à vontade soberana do Estado.

Assim a paz estabelecida pela instituição do Estado e efetivada através da sua soberania ilimitada, é também a condição de possibilidade para o exercício de uma série de atividades privadas, tais como as artes, a ciência, o trabalho e o usufruto da propriedade desenvolvida no interior da sociedade civil que dependem daquelas ações humanas não efetivamente constrangidas ou impedidas legalmente de se realizarem.

\footnotetext{
de autoridade, agir contra as razões da paz - ou seja, contra as leis da natureza - estará usando seu poder para um fim que não é o da segurança do povo. E ainda, tal como a segurança do povo dita a lei através da qual os príncipes aprendem qual é o seu dever, também ela Ihes ensina uma arte que haverá de proporcionar benefícios a eles próprios; pois o poder dos cidadãos é o poder da cidade, isto é, daquele que tem a regra suprema da cidade" (2002a, p. 198).
} 


\section{Referências:}

BARBOSA FILHO, B. Condições de autoridade e autorização em Hobbes. Revista de filosofia política. Porto Alegre, n. 4, pp. 63-75, 1989.

BERNARDES, J. Hobbes a liberdade. Rio de Janeiro: Jorge Zahar, 2002.

BOBBIO, N. Thomas Hobbes, Rio de Janeiro: ed. Campus, 1991.

BRANDT. F. Thomas Hobbes' mechanical conception of nature. London: Hachette, 1928.

GAUTHIER, D. The Logic of Leviathan: The Moral and Political Theory of Thomas Hobbes. Oxford: Oxford University Press, 1979.

KRAUS, J. The Limits of Hobbesian Contractarianism, Cambridge, Cambridge University Press, 1993.

LEBRUN, G. O que é Poder. São Paulo: Abril Cultural/Brasiliense, 1984.

McNEILLY, F. S. The Anatomy of Leviathan. New York, St. Martin's, 1968.

HAMPTON, J. Hobbes and the Social Contract Tradition, Cambridge, 1986.

HELLER, H. Teoria del Estado. Trad. Luís Tobío. Buenos Aires: Fondo de Cultura Económica, 1990.

HOBBES, T.. Leviathan, or The Matter, Forme and Power of a Commonwealth Ecclesiasticall and Civil. Ed. C. B. Macpherson. Harmondsworth: Penguin Books, 1968. (Leviathan).

. Do cidadão. Elementos Filosóficos a Respeito do cidadão. Tradução de Renato Janine Ribeiro. São Paulo: Martins Fontes, 2002a.

. De Cive. The English version in the first edition philosophical rudiments concerning government and society. A critical edition by Howard Warrender. Oxford: Clarendon Press, 1983.

. Elementos da lei natural e política. Trad. Fernando Dias Andrade. São Paulo: Ícone, 2002b. (The Elements of Laws).

. Elements of Philosophy Concerning Body. The Metaphysical system of Hobbes (Metaphysical Writings). Ed. Mary Whinton Calkins. Second edition. Illinois: La Salle, 1948. (De Corpore).

. Hobbes's Treatise Of Liberty and Necessity. In: Hobbes and Bramhall on Liberty and Necessity. Ed. Vere Chappel. Cambridge University Press, 1999.

PITKIN, H. Hobbes's Concept of Representation - part I. American Political Science Review, vol. 58, pp. 328-40, 1964.

POLIN, R. Politique et philosophie politique chez Hobbes, Paris: P.U.F., 1953.

STRAUSS, L. The Political Philosophy of Hobbes. Its Basis and its Genesis. Chicago: University Press Chicago, 1963. 
SPRAGENS, T. A. The Politics of Motion: The World of Thomas Hobbes. University Press of Kentucky, 1973.

SKINNER, Q. Razão e retórica na filosofia de Hobbes. São Paulo: UNESP, 1999a.

SORELL, T. The Cambridge Companion to Hobbes. New York: Cambridge University Press, 1996.

. Hobbes. In: The arguments of Philosophers. London: Routledge, 1991.

(Primeira edição em 1986 pela Routledge \& Kegan Paul, London).

TERREL, J. Hobbes, Matérialisme et Politique. Paris: J. Vrin, 1994.

WATKINS, J. W. N. Hobbes' System of Ideas. London: Hutchinson University Library, 1965.

ZARKA, Y. C.. Philosophy and Politics in Hobbes. The Philosophical Quarterly, vol. 5, n. 19, pp. 125-146, 1955.

E-mail: delmomattos@hotmail.com

Recebido em: Abril de 2011

Aprovado em: Maio de 2011 